\title{
Influence of International Trade on China Economic Growth
}

\author{
Wenhu Zhang ${ }^{1, \text { a }}$ \\ ${ }^{1}$ Xi'an International University, Xi'an, Shaanxi, 710077 \\ ${ }^{a}$ email
}

Keywords: International Agricultural Trade; Economic Growth; Research

\begin{abstract}
Since the reform and opening up, China's agricultural trade has made a good development. Which occupies an important position in the world. However, the gradual emergence of China's agricultural products in international trade "deficit normalization" phenomenon, and this phenomenon can not be reversed in the short term. Chinese agriculture in the national economy as a whole to share the benefits of global economic integration at the same time, the emergence of fierce competition in the market, where price fluctuations, industrial restructuring has brought a great impact. This paper focuses on the development of international trade in agricultural products and its impact theory, industrial structure adjustment and the role of China in international trade of agricultural products in-depth analysis to explore the contribution of International Trade on China's economic growth.
\end{abstract}

\section{Introduction}

Chinese international agricultural trade deficit trend can not be reversed in the short term, and have an adverse impact on China's agriculture and economic growth [1]. So, pay attention to maintain an appropriate level of scale and rational structure of agricultural trade deficit is the current important task. The need to increase investment in science and technology, so that the development of agriculture in international trade stability; improve the flow mode of agricultural products, improve the efficiency of international agricultural trade; optimize the economic structure, improve the comprehensive competitiveness of agriculture. In this paper, the impact of International Trade on China's economic growth to be studied.

\section{Theoretical Analysis of International Trade of Agricultural Products and Their Impact}

International trade theory is produced in the context of the next industrial revolution, for the study of international trade in developed countries, focusing on industrial products, agricultural products in, to a relatively small [2]. Which is mainly due to the international trade and economic growth theory itself has been involved in agricultural products. Secondly because Western countries have realized industrialization, involving a relatively small agricultural sector in developed countries. For agriculture, it has been modernized and industrial development, but also gradually got the government's attention, which occupies an important position in international competition, so the problem of agriculture in the liberalization process need not have more concerns. Compared with other agricultural products, agricultural production and natural economic reproduction two important features make it unique. International agricultural trade is the most important part in international trade, which also exists in the theoretical basis of the theory of international trade.

International trade is not only the production and supplement domestic consumption, but also the role of regulation. It has an important impact on the development of domestic industries. Between international trade of agricultural products and agricultural growth has a close relationship, which exists in the international trade and economic growth among. But agriculture and its production has a certain particularity, the relationship between international trade of agricultural products and agricultural growth also has a certain uniqueness. Theory of development of agricultural industry contains many factors, agricultural development, better able to analyze the relationship between international trade of agricultural products and agricultural growth between.

In the modern theory of economic growth, which led to long-term economic growth is mainly 
due to increase and improve the supply of total factor productivity feature, while the short term, the factors determining economic growth in demand, which needs three areas, namely, investment demand, consumer demand and net export demand.

\section{The Role of Industrial Structure Adjustment of China Agricultural Trade}

Between international trade and industrial structure are closely related, both of which reached the mutually reinforcing role, but also has the effect of mutual restraint. The main factors that determine the structure of international trade of industrial structure, the industrial structure of the international trade structure has a restricted role. From the fundamental point of view, the international trade structure is formed in the industrial structure of spatial expansion. So, we have a great connection between the two.

International trade for the adjustment of domestic industrial structure can be produced by several ways: First, international trade and changes in export-oriented and import-substituting industries factor inputs of labor and capital to achieve. Second, the international trade by addressing domestic structural excess or shortage problem, upgrade the industrial structure. Third, increase the intensity of international trade and technological innovation systems to optimize the industrial structure. Fourth, international trade provides useful information and guidance adjust the industrial structure.

International agricultural trade is an important part of international trade, its impact on the industrial structure mainly in three aspects: First, the international trade of agricultural products directly affect the adjustment of agricultural structure. The second is the adjustment of agricultural structure to promote development of agricultural economy and generating relations with other related industries, and a direct impact on a country's industrial structure. Third, the international trade of agricultural raw materials imports by type of agricultural products, the obstacles of domestic agricultural production, laying a good foundation for the development of related industries, thus affecting the three industrial structure adjustment.

With the rapid development of China's economy, people's living standard has been improved, the rapid development of the food aspect, people continue to improve the structure of food consumption, which gradually increases for meat food consumption, vegetable consumption is gradually reduced, which so that kind of situation of China's agricultural production structure has been continuously optimized. Resulting in a steady increase in output structure of agriculture, animal husbandry and fisheries, which has significantly improved.

It is the main form of labor-intensive exports of agricultural products, which has a high proportion compared with the usual upgrade. Gardening and aquatic products which share compared with previous years has significantly improved, including grain and other exports has dropped significantly. Bulk products become China's major agricultural exports.

Since the reform and opening up, China's industrial structure adjustment made a big proportion of primary industry in GDP decline, the second long-term stability in the industry between $40 \%$ to $50 \%$, the tertiary industry has been significantly increased.

With the rapid development of China's economy, one of the most prominent feature is the change between the adjustment of industrial structure and industrial labor factor mobility, although the restructuring will affect economic fluctuations, but the Industrial Structure Change on China's economic growth has a certain influence. The main performance in these areas: First, the transit of industrial structure of China's economic growth plays an important role, in which the backward industries in transition is the most important part. From agriculture into manufacturing-based industrial structure upgrading is to make China's rapid economic growth of the important reasons. Second, the Industrial Structure Change on China's contribution to economic growth, there is a decreasing trend, China's economy is still in the future may benefit from the Industrial Structure Changes. 


\section{Systematic Review of the Effect of Agricultural Products International Trade on China Economic Growth}

Open the current economic conditions, mainly by consumption, investment and net exports constitute national income [3]. These three are an important factor in promoting economic growth, a direct impact on the growth rate and the quality of the national economy. Agricultural prices affect the price system by the general price level of society, investment demand, consumer demand and net export demand also has a direct impact, and thus a greater impact on national income. General price promotion to promote economic development, but if the long-term price level fluctuations, the adverse impact on economic growth.

Economic growth is based on the increase in the labor force, capital accumulation and technological progress basis. The increase in economic growth is the most important part of the structure of benefits, through industrial restructuring can effectively promote economic growth. For the way industrial restructuring economic growth mainly in the following ways: First, the sophistication of the industrial structure, low productivity sectors will be transferred to higher-productivity sectors, leading to high productivity continued to expand, while productivity sectors gradually reduced, the department structure appears among changes in the industrial structure sophistication towards development, so as to enhance overall productivity. The second is the rationalization of the industrial structure, the flow of the economy more balanced development between departments, improve the situation related sector between departments, enhance the overall social productivity. Third, from a long-term point of view, in the shadow of the elements within the industry elements transferred directly between industry supply and demand, thereby affecting productivity. Fourth, through the combination of different industries, the impact on the economies of scale.

The degree of optimization of industrial structure and economic growth has great links, economic growth is built on the basis of reasonable industrial structure. Economic growth in equilibrium conditions, lower domestic and foreign demand and technological development suited to the industrial structure, resource allocation is reasonable, it is possible to make the total economy sustained improvement. But if the phenomenon of imbalance, or do not meet the market demand, the industrial structure is relatively backward, it will lead to economic growth rate is too slow. At the same time, changes in industry structure will also affect the growth of the total economy. Economic growth and industrial structure is the most important part, occupies an important position in the national economic system. The emergence of new technologies to promote the growth of the national economy. But it must be based on reasonable industrial structure, it will play an important role if the phenomenon of industrial structure imbalance, then the impact on the diffusion of technological innovation, economic growth can not be achieved.

Agricultural Products International Trade on Chinese agricultural prices conductivity has obvious benefits for the Chinese agricultural prices affect the price level of benefits is also very significant. In other words, the expansion of agricultural imports and exports will increase prices of agricultural products in China, and the rise in agricultural prices will have an impact on China's price level, and ultimately affect the prices of agricultural products PPI. Price transmission ripple effect caused by the international trade of agricultural products to China's economic growth has made a great contribution. Including the impact on the growth of China's agriculture, as well as the impact on China's economic growth.

Agricultural Products International Trade and China is not only the direct agricultural structure closely linked, and there is the three industrial structure adjustment effect [4]. China Agricultural growth was mainly influenced by the import and export of agricultural products caused by an impact and relevance of inter-industry and tertiary industries, which have an impact on the entire economic structure. Important source of economic growth is derived from structural factors, restructuring China's economic growth and the role of international trade in agricultural produce has a direct connection. Mainly in the agricultural impact of international trade on agricultural growth, as well as the restructuring effects of international trade of agricultural economic growth. 
An important factor affecting agricultural growth is the international structure of agricultural trade. But fundamentally, its agricultural growth factor inputs and output factors determine the efficiency of self-development system.

\section{Conclusion}

All in all, the international trade of agricultural products to China's economic growth are closely linked. Agricultural Products International Trade on economic growth has a significant impact. Firstly, on the development of international trade of agricultural products and their impact theory analysis and adjustment of industrial structure of China Agricultural Trade action, we discussed international trade of agricultural products to China's economic growth in the contribution of systematic reviews.

SPC (Statistical Process Control, SPC) is through the use of techniques such as statistical process.

The Introduction of Control Chart. In the production process, when the influence of the only.

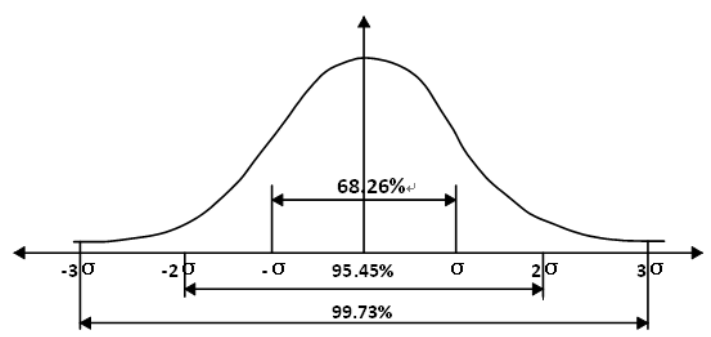

Figure 1. Distribution plot

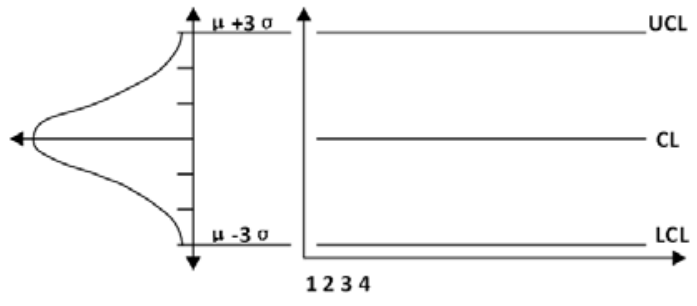

Figure 2. Principle control chart

\section{Acknowledgements}

Fund Project: the National Social Science Fund Project (13xk8008);

Ministry of Education, "New Century Talents Support Program" (NCET-13-0925);

\section{References}

[1] Jia Xinzhang, Li Jingyuan. Electronic Industry, Vol. 6 (2004) No 53, p.25-26

[2] Peng Sue, Wang Yunhui, Wang Qunyong. Electronic Industry, Vol. 12 (2005) No 27, p.74-76

[3] Qian Xiyuan, Jing Jianfen, Hou XuSiem. Computer Engineering, Vol. 30 (2004) No 19, p.144-145

[4] Wang Kuailiang. Mining machinery, Vol. 29 (2008) No 27, p.21-23

[5] Zhang Gongxu, Sun Jing. New Quality Management, Vol. 8 (2003) No 27, p.57-60

[6] M. Colledani, T. Tolio. CIRP Journal of Manufacturing Science and Technology, Vol. 4 (2011) No 27, p. 281-289

[1] Yao modernization of agriculture, population growth, the impact of trade policies on the international competitiveness of agricultural products - Empirical Analysis Based on Cointegration and VEC model [J]. Economic Survey, 2014,02: 50-56.

[2] Xu Qing, Fan Ying, Wu Fang Wei China zero tariff policy background - ASEAN Free Trade Area of China Agricultural Trade Simulation economic impact analysis [J] World Economic Research, 2011,11: 81-86 + 89.

[3] Liuqiao Ling, Wang Qi, Yong study economic growth, international trade and the relationship between emissions - Empirical Analysis Based on the United States and China SO_2 emissions [J] China Population, Resources and Environment, 2012,05:... 170176.

[4] Yang Li green barriers and countermeasures for Chinese agricultural products in international trade [J] Dandong Teachers College, 2003,04: 44-46 + 40. 